\title{
Platycopia compacta n. sp., the Second Species of Platycopioida (Crustacea: Copepoda) in the Indo-Pacific Region, with Remarks on Development, Feeding, Swimming, and Zoogeography
}

\author{
Susumu Ohtsuka ${ }^{1 *}$, Ho Young Soh ${ }^{1}$ and Hiroshi Ueda ${ }^{2}$ \\ ${ }^{1}$ Fisheries Laboratory, Hiroshima University, 5-8-1 Minato-machi, \\ Takehara, Hiroshima 725-0024, Japan \\ ${ }^{2}$ Marine Biological Station, Ehime University, Nakajima-cho, \\ Onsen-gun, Ehime 791-4502, Japan
}

\begin{abstract}
Platycopia compacta new species (Copepoda: Platycopioida) is described from the hyperbenthic zone in the Tokara Islands, southern Japan. This is the second species of the order in the Indo-Pacific region, and the eighth species of the genus. The present new species is distinguishable from the closely related $P$. inornata from the Bahamas by (1) the formation of allobasis in the antenna; (2) two unequal setae on the basal exite of the maxillule; (3) the intermaxillipedal process with only 3 pairs of prominences at tip; (4) the fusion of the coxa and basis in leg 3; and (5) the fusion of the second and third endopod segments in female legs 3-5. Copepodid stages III, V, and VI are compared with those of $P$. orientalis collected from Okinawa, and differ in the developmental patterns of the antennule and legs. The presence of an intermaxillipedal process and gut content analysis revealed that Platycopia is carnivorous. The armature of legs 2-5 of the hyperbenthic genus Platycopia is stouter than that of cavernicolous platycopioids, which indicates that Platycopia may penetrate into loose sediment, whereas the latter group might be more adapted to pelagic life. The horizontal distribution of the genus Platycopia apparently exhibits a full Tethyan track.
\end{abstract}

\section{INTRODUCTION}

Hyperbenthic and cavernicolous copepods have provided significant new information about the morphology, zoogeography, ecology and phylogeny of the maxillopodan subclass Copepoda. Some calanoid genera such as Exumella, Metacalanus, Paramisophria, and Stephos are broadly distributed in both the hyperbentic zone and marine caves and indicate faunistic similarities between the two realms (cf. Boxshall et al., 1990; Bowman, 1976; Jaume and Boxshall, 1995a; Ohtsuka et al., 1993b,1994; Riera et al., 1991). Recently numerous new families, genera, and species of copepods have been discovered from anchialine caves (e.g., Fosshagen and lliffe, 1985, 1988, 1989, 1991, 1994; Jaume and Boxshall, 1995a,b, 1996a,b; Ohtsuka et al., 1993a,b; Rocha and lliffe, 1991). These have shed new light on phylogenetic relationships within each copepod order (Boxshall, 1989; Ho, 1994) and brought into question the totality of the Messinian Salinity Crisis in the Mediterranean Sea about 5.5 Myr BP (Jaume and Boxshall, 1996b).

During our investigation of hyperbenthic copepods we have found another species of Platycopia, which belongs to the hyperbenthic/cavernicolous copepod order Platycopioida, in the Nansei Islands, southern Japan. This is the second species of the order in the Indo-Pacific region and the eighth species of the genus worldwide. The present paper describes the new species with remarks on its development, feeding , swimming, and zoogeography.

\section{MATERIAL AND METHODS}

Copepods were collected with a dredge (mouth $50 \mathrm{~cm}$ wide, 15 $\mathrm{cm}$ high; mesh size $5 \mathrm{~mm}$ ) at $67 \mathrm{~m}$ depth off Kuchino Island, Tokara Islands, south of Kyushu, Japan ( $\left.30^{\circ} 00.82^{\prime} \mathrm{N}, 129^{\circ} 53.92^{\prime} \mathrm{E}\right)$, on June 1, 1997 (local time 0815-0847). Sediment was stirred in sea-water several times and the supernatant was filtered with a plankton net (mesh size: $0.1 \mathrm{~mm}$ ). Copepods were fixed in 10\% neutralized formalin/sea-water immediately after filtering.

The type specimens are deposited in the Natural History Museum and Institute, Chiba. Terminology follows Huys and Boxshall (1991).

\footnotetext{
* Corresponding author: Tel. +81-846-22-2362; FAX. +81-846-23-0038.
} 


\section{DESCRIPTION}

Order Platycopioida Fosshagen, 1985

Family Platycopiidae Sars, 1911

Genus Platycopia Sars, 1911

Platycopia compacta new species

(Figs. 1-6)

Material examined.-Holotype: adult female (body length $0.76 \mathrm{~mm}$ ), dissected and mounted on 14 glass slides, CBM ZC 4035. Paratype: adult female (body length $0.81 \mathrm{~mm}$ ), whole specimen, CBM ZC 4036. Non-types: copepodid V female (body length $0.74 \mathrm{~mm}$ ), dissected and mounted on 4 glass slides; copepodid V male (body length $0.62 \mathrm{~mm}$ ), dissected and mounted on 2 glass slides; copepodid III (body length $0.47 \mathrm{~mm}$ ), dissected and mounted on 1 glass slide.

Description.-Adult female (holotype). Body (Fig. 1A,B) compact. Prosome about 2.8 times as long as urosome; cephalosome and first pedigerous somite incompletely fused, without distinct arthrodial membrane; fifth pedigerous somite produced posteriorly into round lobe reaching beyond middle of first abdominal somite; several developing ova observed in posterior part of prosome in dorsal and lateral view. Rostrum (Fig. 1C) sharply pointed, ventrally directed, without filaments at tip. Urosome (Fig. 1D) 5-segmented; genital somite small, almost concealed beneath dorsal extension of fifth pedigerous somite; paired slit-like gonopores (arrowed in Fig. 1D) located ventrally, slit-like; first to third abdominal somites with posterior margin finely striated; third abdominal somite protruded dorsoposteriorly into w-shaped plate partly covering anus; fourth abdominal somite prominent ventroposteriorly. Caudal rami (Fig. 1D,E) symmetrical, each with triangular dorsal process; seta I rudimentary, seta II slender, setae III-VI plumose; setae IV and $\mathrm{V}$ with finely punctate proximal surface.

Antennule (Fig. 2A) 23-segmented. First segment with two longitudinal ridges and elongate, heavily chitinized anterior seta. Armature and fusion pattern as follows: I-III may be incorporated in first segment, which is not traceable based on elements; IV-VI-6 + ae; VII-2 + ae; VIII-1 short spiniform seta; IX-2 + ae; X-1 + 1 short spiniform seta; XI-2 + ae; XII-1; XIII-1 + 1 short spiniform seta; XIV-2 + ae; XV-1; $\mathrm{XVI}-1+\mathrm{ae}$; XVII-0; XVIII-1; XIX-0; XX-1; XXI-1+ae; XXII-0; XXIII-1; XXIV—1; XXV-1+ae; XXVI-2; XXVII$1+1 ; \mathrm{XXVIII-4}+$ ae.

Antenna (Fig. 2B) with unarmed coxa and basis. Endopod with first segment completely fused to basis to form allobasis; second and third segments incompletely coalesced, bearing 3 and 7 setae, respectively. Exopod indistinctly 7-segmented; setal formula 1, 0, 1, 1, 2, 1, 4.

Mandibular gnathobase (Fig. 2C) bearing 1 monocusped tooth and 4 bicusped teeth. Mandibular palp (Fig. 2D) with unarmed basis. Endopod unisegmented, with 7 terminal setae. Exopod 4-segmented, first to fourth segments, respectively, with $0,2,1$, and 2 setae.

Maxillule (Fig. 2E) well developed; praecoxal arthrite expanded, bearing 6 stout, multicusped spines and 6 setae, 2 setae of which being originated from center of anterior sur- face; coxal endite with 3 setae; basal exite (arrowed in Fig. $2 \mathrm{E})$ lobate, bearing 2 setae of unequal length; proximal basal endite elongate, bearing 3 terminal spinulose setae; distal basal endite probably represented by a knob with 2 unequal setae; both rami completely incorporated into basis, bearing 4 setae in total.

Maxilla (Fig. 2F) stout; 2 praecoxal, 2 coxal, and 1 basal endites bearing $4,1,3,3$, and 3 setae, respectively, one seta each on second coxal endite and on basal endite fused to segment. First endopod segment completely fused to basis, represented by 1 spiniform seta; second to fourth segments each bearing 1 spiniform seta; third and fourth segments with 1 and 2 setae, respectively, in addition to spiniform seta.

Maxilliped (Fig. 3A) with praecoxa and coxa incompletely coalesced; coxa with 2 spinulose, subterminal setae; basis bearing 2 inner setae, one of them being rudimentary; endopod 6-segmented, setal formula 1, 2, 2, 1, 1, 4. Intermaxillipedal process (Fig. 1B,F) with 3 pairs of anteriorly directed, acute prominences at tip.

Leg 1 (Fig. 3B) with 2-segmented rami; coxa unarmed, produced into acute outer process subterminally; basis expanded, bearing plumose setae near base of endopod. First endopod segment with longitudinal groove on anterior surface along basal seta, segment produced at outer distal corner. First exopod segment unarmed, prominent at outer distal corner; second with acute prominence and row of setules along outer margin and 6 setae, outermost more heavily chitinized than others. Leg 2 (Fig. 3C) with 3-segmented rami. Legs 3 (Fig. 4A) and 4 (Fig. 4B) with second and third endopod segments not fully separate on posterior surface; both legs similar, but differing in: (1) coxa and basis separate in leg 4 and incompletely fused in leg 3; (2) third endopod segment bearing 5 spiniform setae in leg 3 but 4 in leg 4; (3) second exopod segment lacking inner seta in leg 3. Leg 5 (Fig. 4C) with expansion along inner margin of basis; second and third endopod segments almost fused, with suture visible on both surfaces. Spine and seta formula of legs 1 to 5 shown in Table 1.

Male unknown.

Copepodid III (CIII) (Although legs 3-5 are damaged in the only individual, it was identified as CIII on the basis of the number of urosomal somites, the number of ramal segments of leg 2 and the presence of leg 5. See Ohtsuka and Boxshall, 1994).-UUrosome 2-segmented. Antennule 15-segmented (Fig. 5); armature as follows: $1-4+$ ae (Fig. 6A); 2-0; 3-1 + ae; 4-0; 5-1; 6-0; 7-1; 8-1 + ae; 9-0; 10-1; 11-1; $12-1+$ ae; $13-2 ; 14-1+1 ; 15-4+$ ae (see Development in Discussion). Antenna with basis completely fused to first endopod to form allobasis. Basal exite of maxillule with 2 setae of unequal length. Maxilliped with only single seta on coxa; basis as in adult female; endopod 4-segmented; setal formula of $1,1,1,4$. Intermaxillipedal process with 2 pairs of prominences at tip. Leg 1 with 2-segmented rami; second exopod segment bearing only 5 setae. Leg 2 (Fig. 6C) with 2-segmented rami; first exopod segment with single outer spine. Legs 3-5 missing.

Copepodid V (CV) female.-UUrosome 4-segmented. An- 


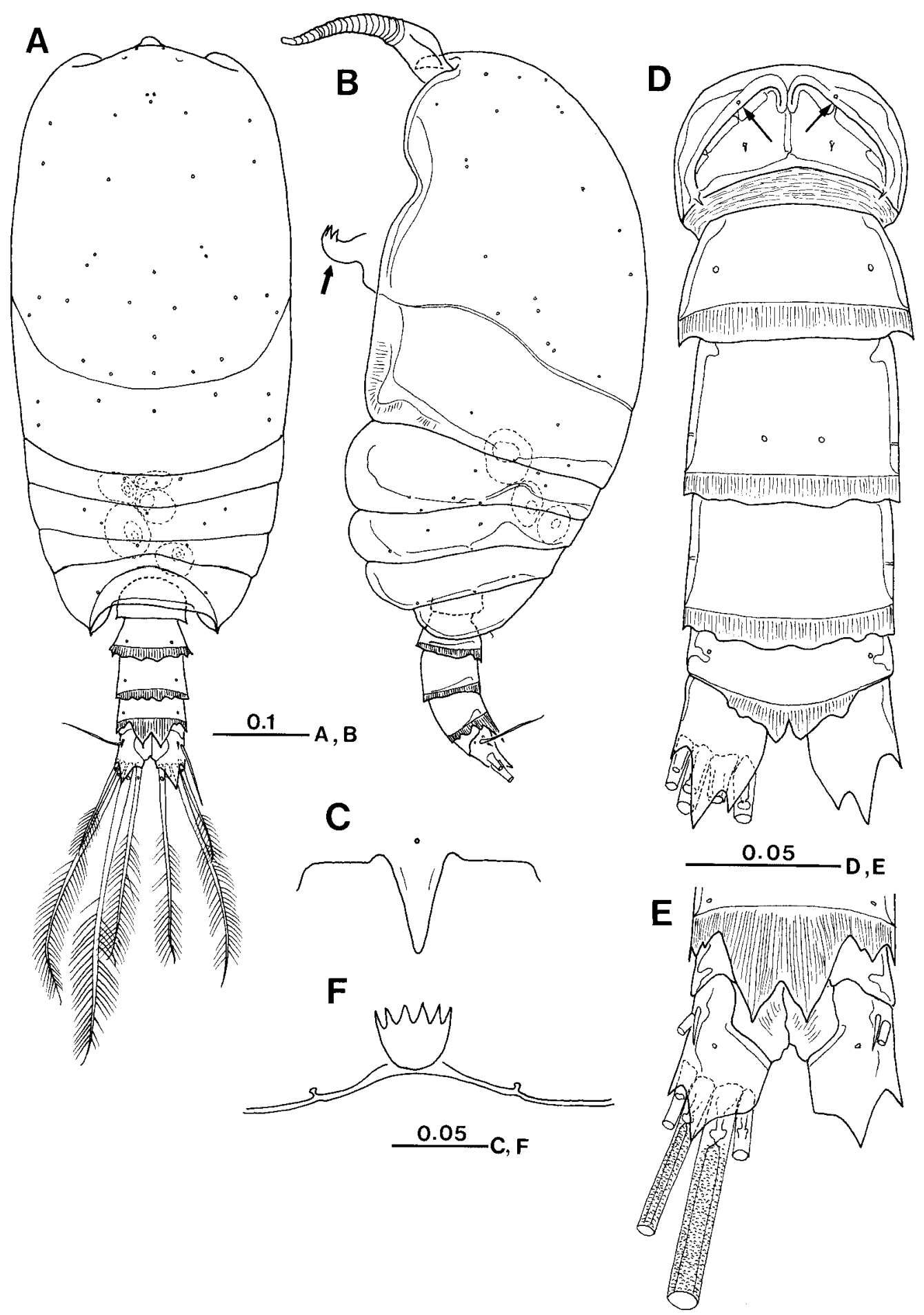

Fig. 1. Platycopia compacta, adult female (holotype). (A) Habitus, dorsal; (B) Habitus, lateral, intermaxillipedal process arrowed; (C) Rostrum; (D) Urosome, ventral, gonopores arrowed; (E) Anal somite and caudal rami, dorsal; (F) Intermaxillipedal process, viewed from ventral side. Scale bars in $\mathrm{mm}$.

tennule 22-segmented (Fig. 5); armature as follows: $1-8+2$ ae (Fig. 6B); 2-1 short spiniform seta; $3-2 ; 4-1$ short spiniform seta; $5-2+$ aesthetasc; $6-1 ; 7-1+1$ short spiniform seta; 8-2; 9-1; 10-1 + ae; 11-0; 12-1; 13-0; $14-1 ; 15-1+$ ae; $16-0 ; 17-1 ; 18-1 ; 19-1+$ ae; $20-2$;
$21-1+1 ; 22-4+$ ae (see Development in Discussion). Basal exite of maxillule with 2 setae of unequal length. Maxilliped as in adult female. Intermaxillipedal process with 3 pairs of prominences at tip. Legs 1 and 2 as in adult female. Leg 3 with 2segmented endopod and 3-segmented exopod; armature as 


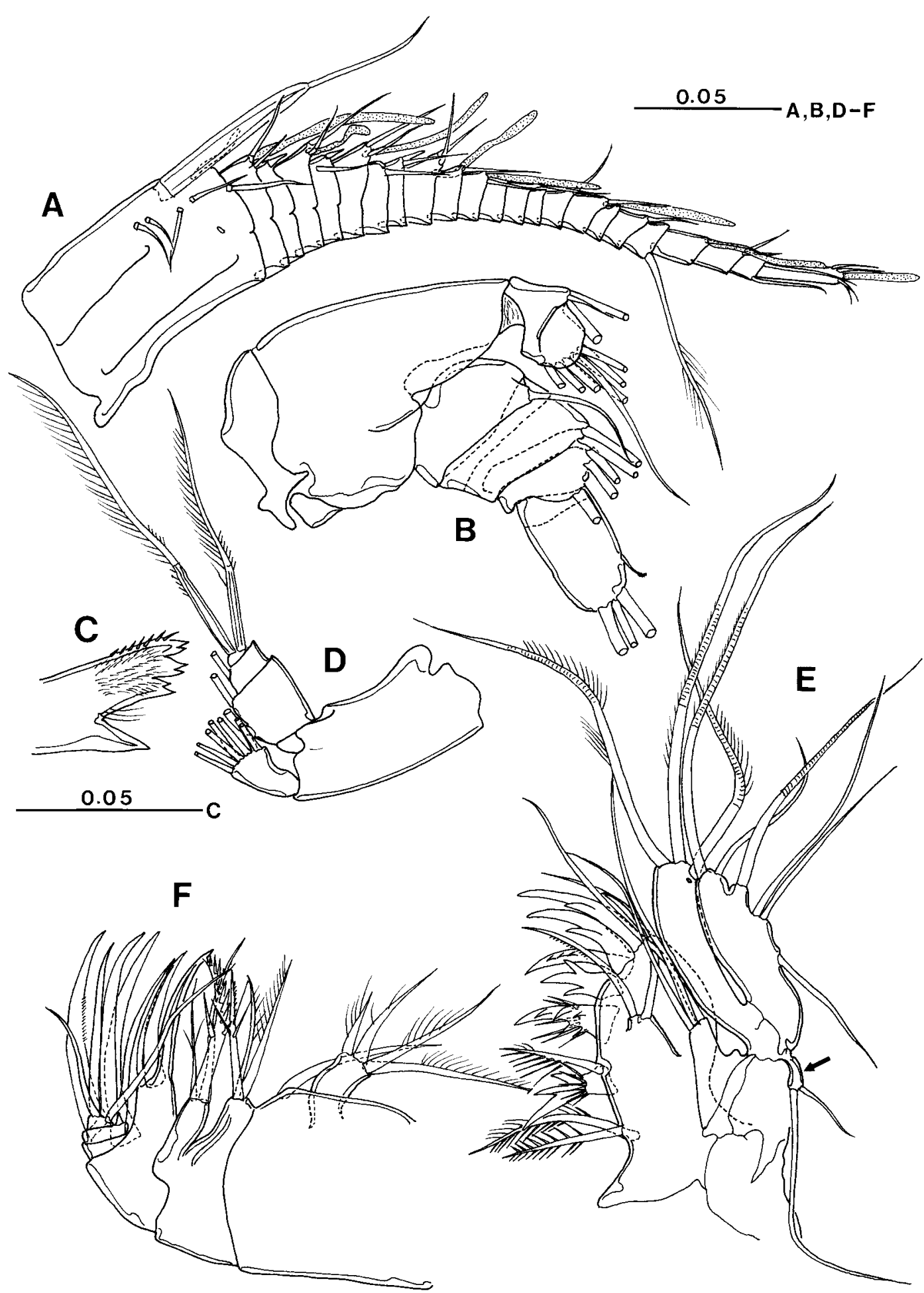

Fig. 2. Platycopia compacta, adult female (holotype). (A) Antennule; (B) Antenna; (C) Mandibular cutting edge; (D) Mandibular palp; (E) Maxillule, basal exite arrowed; (F) Maxilla. Scale bars in $\mathrm{mm}$.

in adult female, but second and third endopod segments not separated, without arthrodial membrane. Leg 4 with 2-segmented endopod and 3-segmented exopod; armature as in adult female, but second and third endopod segments not separate. Leg 5 (Fig. 6D) with intercoxal sclerite not fully sepa- rated from coxa; 2-segmented rami; first endopod unarmed, second bearing 6 spines; first exopod segment with single outer spine, second segment bearing 4 flanged spines and 3 short spines.

Copepodid V (CV) male.-UUrosome, antennule (Fig. 6B), 


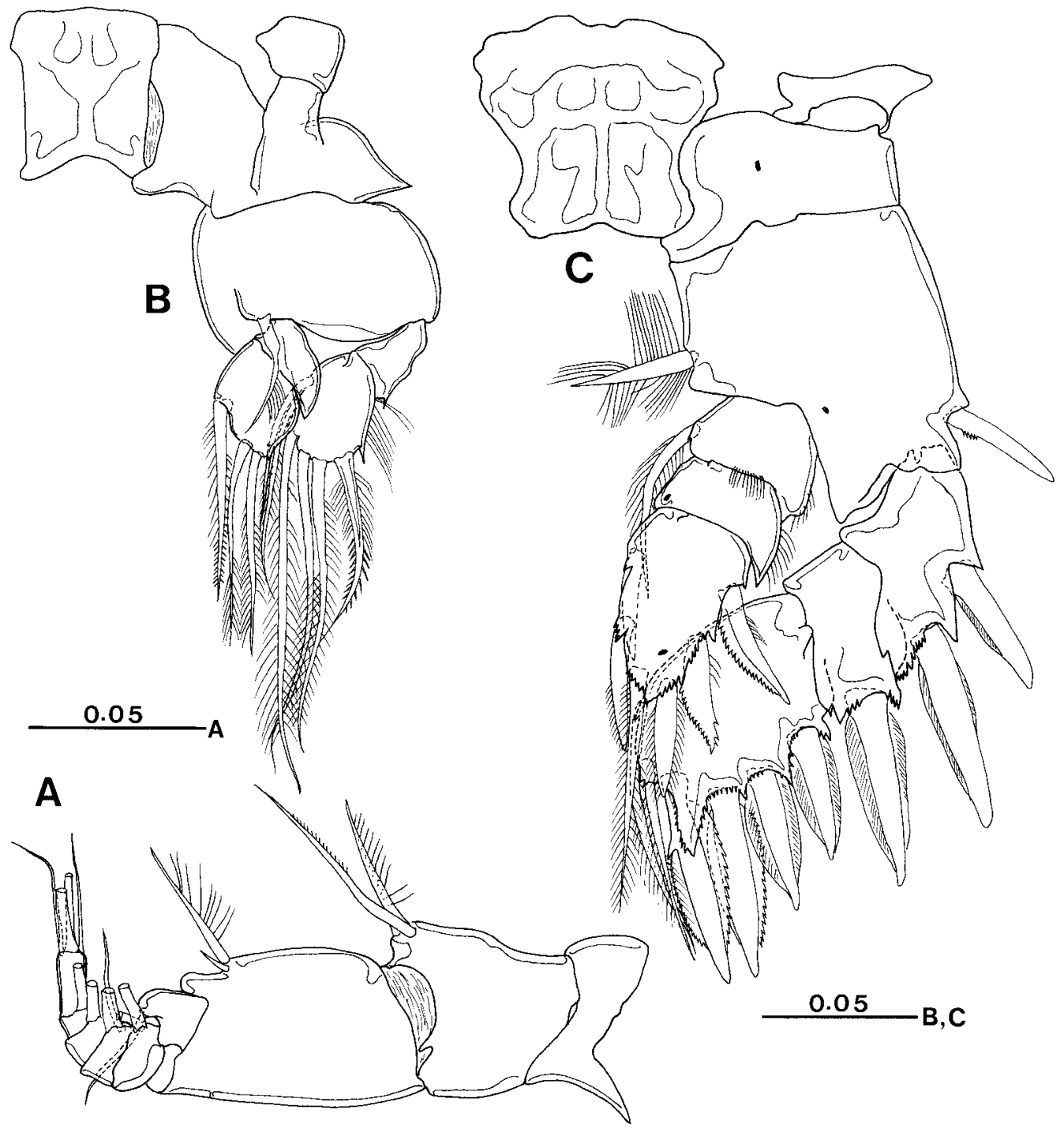

Fig. 3. Platycopia compacta, adult female (holotype). (A) Maxilliped; (B) Leg 1, anterior; (C) Leg 2, anterior. Scale bars in mm.

basal exite of maxillule, intermaxillipedal process, and legs 1 4 as in CV female. Leg 5 (Fig. 6E) with intercoxal sclerite not fully separated from coxa; 2-segmented rami; second endopod segment with 6 short spines; second exopod segment bearing 4 flanged spines ( 2 missing) and 2 short spines.

Etymology.-The specific name "compacta" (Latin compactus meaning plump) is derived from the compact prosome of the new species, compared with that of $P$. orientalis first collected from Japan.

Comparison.-The mouthparts and leg 1 of species of the genus Platycopia exhibit no remarkable differences while the armature and fusion pattern of legs 2-5 are the important characters for distinguishing between species (Wilson, 1946; Ohtsuka and Boxshall, 1994). The presence or absence of the intermaxillipedal process is also important. Some species such as $P$. inornata Fosshagen, 1972 and $P$. perplexa Sars, 1911 are furnished with it (see Sars, 1911; Huys and Boxshall, 1991), whereas P. orientalis Ohtsuka and Boxshall, 1994 lacks a distinct process. Although some other congeners may also bear a process, it was not mentioned in their original descriptions.

The present new species closely resembles Platycopia inornata, $P$. perplexa, $P$. robusta Andronov, 1985 , and $P$. sarsi M.S. Wilson, 1946 in: (1) 3-segmented rami in legs 2-4 (symplesiomorphy); (2) the first exopod segments of legs 3 and 4 of adults bearing 1 inner seta (symplesiomorphy). Female $P$. perplexa and $P$. robusta both lack an inner seta on the first exopod segment of leg 5 (synapomorphy) while $P$. inornata and the new species carry one (symplesiomorphy). Since only males are known in $P$. sarsi, it is impossible to compare the female legs 5 . The present new species is distinguishable from $P$. inornata in: (1) the basis and endopod of the antenna being completely fused (separate in $P$. inornata); (2) the 2 setae on the basal exite of the maxillule being of unequal length (almost equal in $P$. inornata); (3) the intermaxillipedal process having 6 spinous prominences at its 


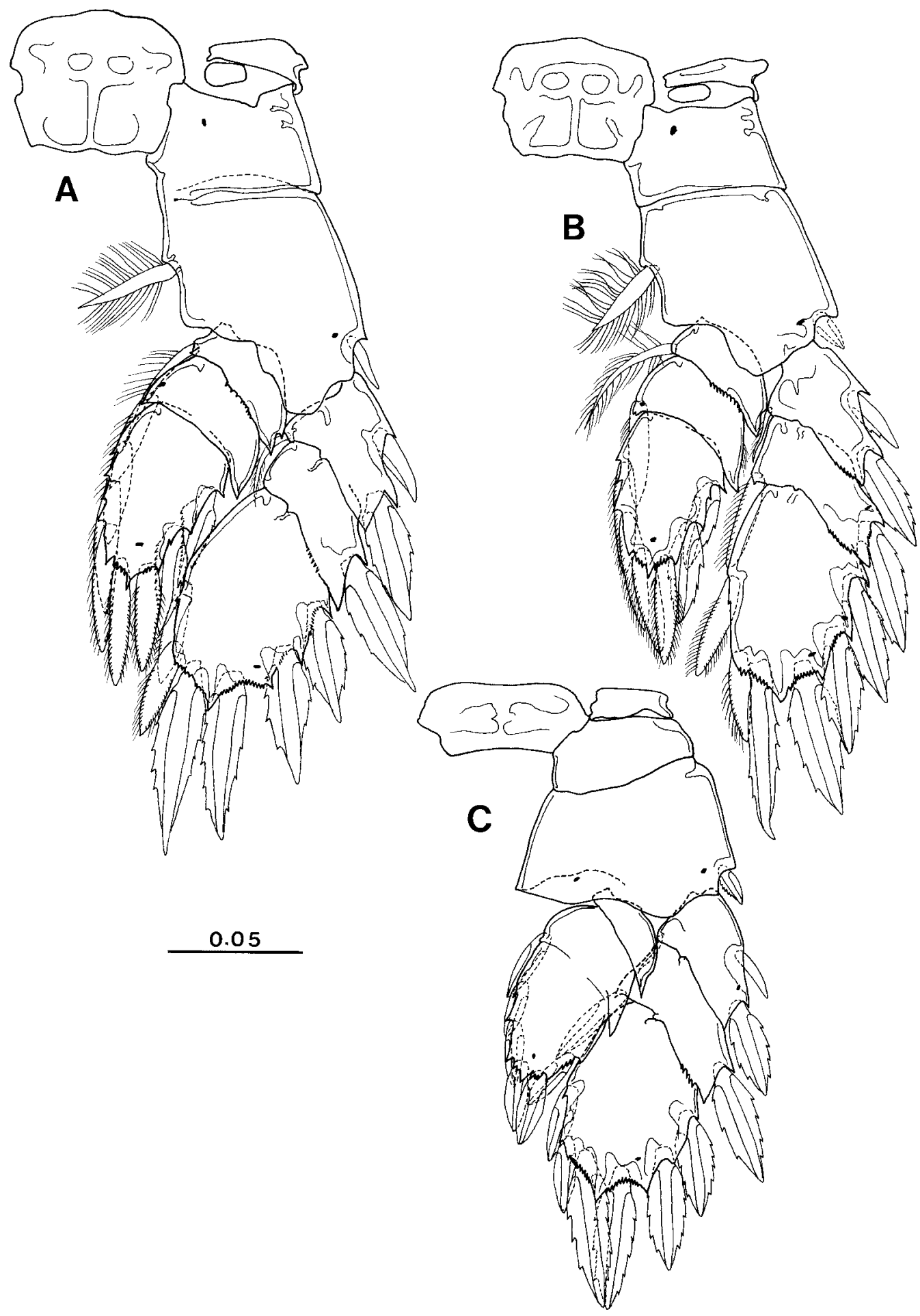

Fig. 4. Platycopia compacta, adult female (holotype). (A) Leg 3, anterior; (B) Leg 4, anterior; (C) Leg 5, anterior. Scale bar in mm.

tip (8 in P. inornata: Huys and Boxshall, 1991, fig.2.1.12); (4) the coxa and basis in leg 3 being fused (separate in $P$. inornata); (5) the second and third endopod segments in legs 3 and 4 being incompletely fused (separate in $P$. inornata); and (6) the second and third endopod segments of the female leg 5 being almost completely fused (separate in $P$. inornata).
Platycopia sarsi was poorly described on the basis of a single adult male and two copepodids by Wilson (1946). The following features differ between $P$. sarsi and the new species: (1) the proximalmost spine on the praecoxal arthrite of maxillule is bifurcate in $P$. sarsi but tricusped in $P$. compacta; (2) the outer subterminal corner of the coxa of leg 1 is round 
Table 1. Seta and spine formula of legs 1 to 5 of Platycopia compacta n. sp. Roman and Arabic numerals indicate spines and setae, respectively.

\begin{tabular}{lcclll}
\hline & coxa & basis & \multicolumn{2}{c}{ exopod } & \multicolumn{2}{c}{ endopod } \\
& & & \multicolumn{1}{c}{$2 \quad 3$} & 1 & \multicolumn{1}{c}{3} \\
\hline Leg 1 & $0-0$ & $0-1$ & $0-0 ; 1,1,4$ & $0-0 ; 0,2,1$ \\
Leg 2 & $0-0$ & $\mathrm{I}-1$ & $\mathrm{II}-0 ; \mathrm{I}-0 ; \mathrm{III}, \mathrm{I}, 2$ & $0-1 ; 0-0 ; \mathrm{II}, 2,2$ \\
Leg 3 & $0-0$ & $\mathrm{I}-1$ & $\mathrm{II}-0 ; \mathrm{I}-0 ; \mathrm{II}, \mathrm{I}, 2$ & $0-1 ; 0-1 ; \mathrm{II}, 2,3$ \\
Leg 4 & $0-0$ & $\mathrm{I}-1$ & $\mathrm{II}-1 ; \mathrm{I}-1 ; \mathrm{III}, \mathrm{I}, 2$ & $0-1 ; 0-1 ; \mathrm{II}, 2,3$ \\
Leg 5 & $0-0$ & $\mathrm{I}-0$ & $\mathrm{II}-1 ; \mathrm{I}-\mathrm{I} ; \mathrm{II}, \mathrm{I}, \mathrm{II}$ & $0-0 ; 0-\mathrm{I} ; \mathrm{I}, \mathrm{II}, \mathrm{II}$ \\
\hline
\end{tabular}

in $P$. sarsi but acutely pointed in $P$. compacta. The late copepodid female described by Wilson (1946) probably corresponds to the fifth copepodid stage because of the 22-segmented antennule, 3-segmented rami of legs 2-4, and 2-segmented rami of leg 5 (cf., Ohtsuka and Boxshall, 1994). In $P$. compacta the fifth copepodid stage of both sexes bears a 2segmented endopod in leg 5 , in which the second and third segments of the adult are not fully separated. Leg 5 of the CV female of $P$. sarsi differs slightly from that of $P$. compacta: the proximal outer spine on the second endopod segment and the proximal inner spine on the second exopod segment are relatively more elongate than those of $P$. sarsi.

\section{DISCUSSION}

\section{Development}

The segmentation and setation of the antennules of $P$. compacta are depicted in Fig. 5. The most proximal antennular segment of female CVI is interpreted as IV-VI based on Huys and Boxshall (1991): "the setation pattern provides no evidence of the fate of the 3 most proximal segments". Although the fourth copepodid stage (CIV) is unknown, the setation of the distal 13 segments are unchanged from CIII to CVI. At the last molt from CV to CVI, an aesthetasc is added into the ancestral segments IV-VI, IX, and XIV; a seta is added to the segment $X$. The first compound segment of $C V$ consists of the ancestral segments IV-VII, the last of which is sepa- rate from the compound segment IV-VI at CVI.

Developmental patterns of antennules, maxillipeds and legs can be compared between $P$. compacta and $P$. orientalis as described by Ohtsuka and Boxshall (1994). In CIII the number of segments of the antennules is 15 in $P$. compacta and 18 in $P$. orientalis. The distal 13 segments (ancestral segments XVI-XXVIII) of $P$. compacta have the same armature as in $P$. orientalis. In $\mathrm{CV}$ the segmentation and setation of the antennules are the same in both species except for the presence of an aesthetasc on the ancestral segment XIV and incomplete separation between the first (precursor of III-VII) and second (VIII) segments in P. orientalis. In CVI (adult female) the ancestral compound segment III (or IV)-VI and segment VII are separate in $P$. compacta and fused in $P$. orientalis. The differences between the armatures of CVI of both species are as follows: an aesthetasc is present on the compound segment IV-VI of $P$. compacta but absent on the part corresponding to IV-VI on the compound segment III-VII of $P$. orientalis; the ancestral segment VII is separate from the compound segment IV-VI in $P$. compacta but incorporated in $P$. orientalis; the ancestral segment XIII bears 1 long and 1 short spiniform seta in $P$. compacta, but only a single long seta in $P$. orientalis. In addition, the appearance of aesthetascs at the molt from $\mathrm{CV}$ to $\mathrm{CVI}$ differs: in $P$. compacta an aesthetasc appears on segments IV-VI, IX, and XIV, whereas in $P$. orientalis only one aesthetasc is added on segment IX.

The development of maxillipeds has so far been unknown in the Platycopioida including $P$. orientalis (Ohtsuka and Boxshall, 1994). In $P$. compacta the numbers of the maxilliped endopodal segments in CV and CIII are 6 and 4, respectively. Therefore that in CIV may be 5 . If the development follows the pattern proposed for the Calanoida by Ferrari (1995), the penultimate endopod segment of CIII can be identified as a precursor of the third to fifth segments of the adult (although Ferrari (1995) regards the first endopod segment as a lobe of the basis, we follow Huys and Boxshall (1991): maxillipeds primitively bear 6-segmented endopod rather than 5-segmented); at the molt from CIII to CIV the third segment of the adult may first appear to result in 5-segmented endopod;

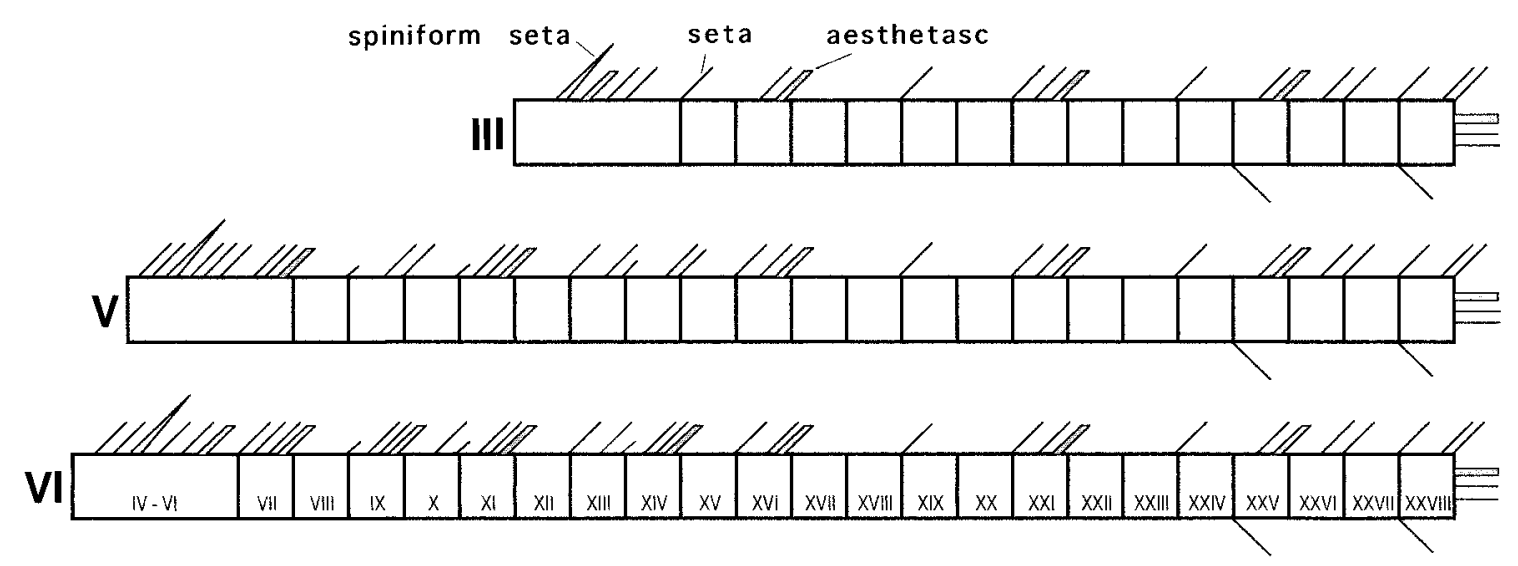

Fig. 5. Schematic illustration of antennules of Platycopia compacta. (III) third copepodid stage; (V) fifth copepodid stage (both sexes); (VI) adult female. Roman numerals indicate the ancestral segment scheme proposed by Huys and Boxshall (1991). 


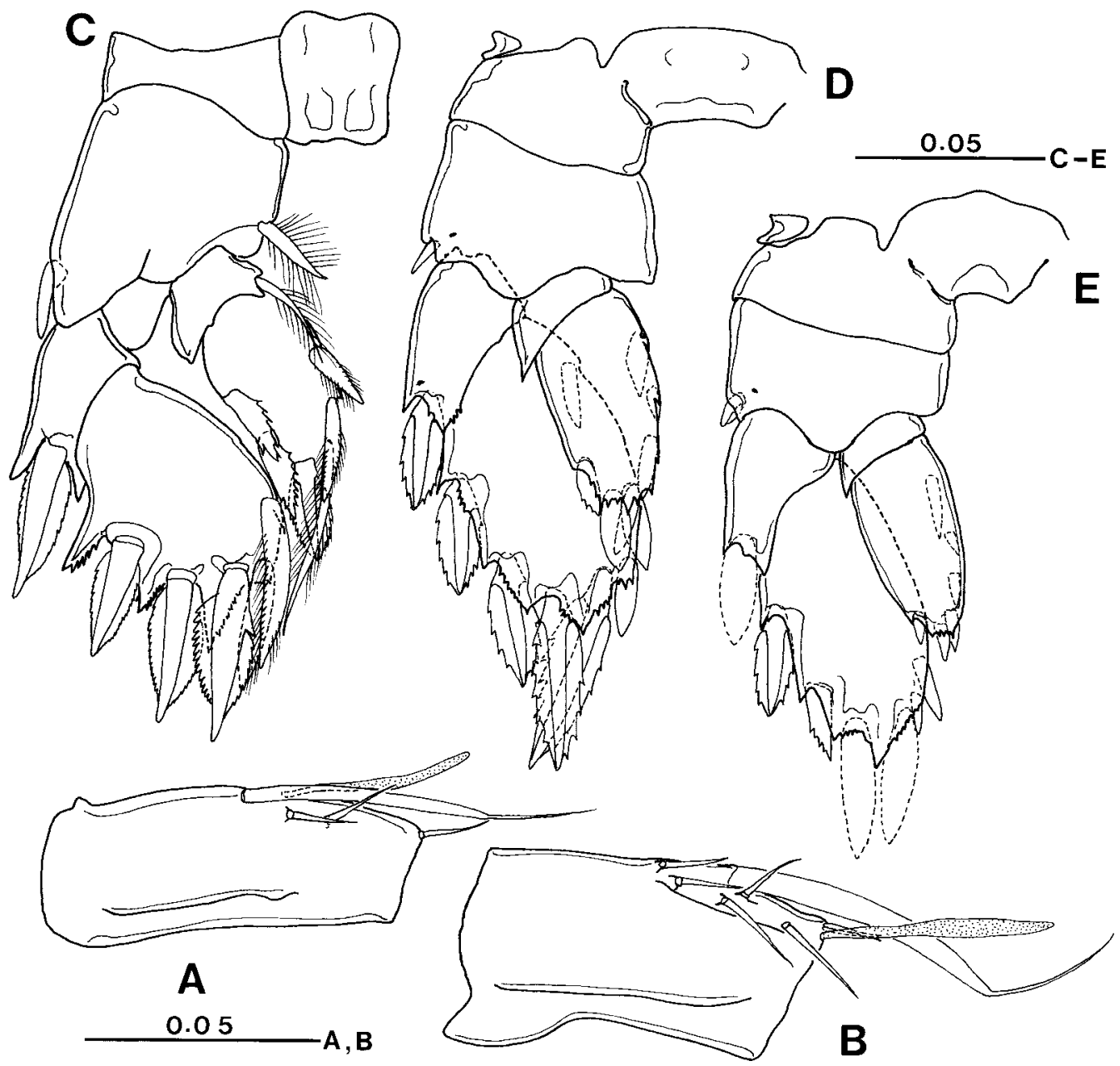

Fig. 6. Platycopia compacta. (A) First segment of antennule of third copepodid stage; (B) First segment of antennule of fifth copepodid stage male; (C) Leg 2, third copepodid stage; (D) Leg 5, fifth copepodid stage female; (E) Leg 5, fifth copepodid stage male. Scale bars in mm.

the fourth segment of the adult could be added at the molt from CIV to CV. In the Calanoida the adult endopod segmentation is completed at CIV (see Ferrari, 1995; Ferrari and Markhaseva, 1996) while in $P$. compacta presumably at CV. The completion of the endopod segmentation may be accelerated in the Calanoida.

The setation of the maxilliped endopod of $P$. compacta is completed probably at $\mathrm{CV}$ as well as the segmentation. Perhaps the setal numbers of the first and sixth endopod segments of the adult are the same from CIII to CVI. Following the pattern of the Calanoida (Ferrari, 1995; Ferrari and Markhaseva, 1996), the setal formula of the endopod of CIV may be 1, 2, 2, 1, 4 .

The developmental pattern of legs 1-5 of $P$. compacta is shown in Table 2 to compare it with the common pattern of copepod leg ontogeny proposed by Ferrari (1988). Simultaneous additions are suspended in both rami of leg 1 here as well as in $P$. orientalis. The developmental pattern of legs 2 and 5 of $P$. compacta almost coincides with the common developmental pattern although the second and third endopod segments of legs 3 and 4 are not fully separated. Probably
Table 2. Pattern of development of legs 1 to 5 of Platycopia compactan. sp. Number of exopod segments + number of endopod segments. Number in parentheses indicates incomplete separation of second and third segments.

\begin{tabular}{rlllll}
\hline & $\operatorname{leg} 1$ & $\operatorname{leg} 2$ & $\operatorname{leg} 3$ & $\operatorname{leg} 4$ & $\operatorname{leg} 5$ \\
\hline Copepodid III & $1+1$ & $2+2$ & missing & missing & missing \\
V & $1+1$ & $3+3$ & $3+2$ & $3+2$ & $2+2$ \\
VI & $1+1$ & $3+3$ & $3+(3)$ & $3+(3)$ & $3+(3)$ \\
\hline
\end{tabular}

separations of these segments are delayed in legs 3 and 4 . In contrast, simultaneous additions during the last molt are suspended in the endopods of legs $2-4$ in $P$. orientalis, which results in 2-segmented endopods in these legs. In CIII a proximal outer spine on the first exopod segment of leg 2 appears in $P$. orientalis (Ohtsuka and Boxshall, 1994), but not in $P$. compacta.

\section{Feeding and swimming}

Little is known about the biology and ecology of the order Platycopioida (Huys and Boxshall, 1991). Platycopia bears 
well-developed maxillulary praecoxal arthrites, maxillae with stout spiniform setae and spines, and an intermaxillipedal process in some species, all of which probably play a role in grasping and holding prey. This is supported by gut content analysis which indicated that the CV female of $P$. compacta had preyed upon copepodids of other copepods

The strong spines and spiniform setae of legs 2-5 of Platycopia imply that it may penetrate loose sediment but not interstitial spaces. The leg armature of the hyperbenthic Platycopia is much stronger than that of the cavernicolous Antrisocopia Fosshagen, 1985 and Nanocopia Fosshagen, 1988, which suggests that Platycopia is more closely associated with sediment than are the cave-dwelling genera (cf., Bowman and González, 1961), which are more adapted to a pelagic life.

\section{Zoogeography}

The order Platycopioida was the first group to diverge from the main lineage of the subclass Copepoda and retains numerous extremely plesiomorphic characters. Platycopioids are restricted to the hyperbenthic zone and anchialine caves in shallow waters (Huys and Boxshall, 1991). All eight species of the genus Platycopia are distributed exclusively in the hyperbenthic zone in the Atlantic and Indo-Pacific Oceans (Huys and Boxshall, 1991; Ohtsuka and Boxshall, 1994; present study), while Antrisocopia Fosshagen, 1985 and Nanocopia Fosshagen, 1988 are monotypic inhabitants of anchialine caves in Bermuda (Fosshagen and Iliffe, 1985, 1988). Since there are numerous anchialine caves and other types of marine caves in the Nansei Islands, southern Japan (Hayami and Kase, 1993), undescribed taxa of the Platycopioida could be discovered in these regions.

The distribution of the genus Platycopia is shown in Fig. 7 on the basis of Huys and Boxshall (1991), Ohtsuka and Boxshall (1994), and the present study. This pattern evidently coincides to a full Tethyan track (circum-tropical through the entire region of the former Tethys Sea) as defined by Stock (1993), who insisted that stygobionts that display such a distributional pattern and have poor dispersal abilities must have existed in place ever since the existence of the Tethys Sea (ca. 120-20 Myr BP). Although the genus Platycopia is not a real stygobiont, the distributions of many hyperbenthic copepods seem to coincide with the full Tethyan track. For example, hyperbenthic calanoid copepods such as Paramisophria, Pseudocyclops, Stephos, and the Ridgewayiidae are distributed in the shallow waters in the Caribbean, the eastern Atlantic, and Indo-West Pacific regions (Boxshall et al., 1990; Fosshagen, 1968a,b, 1970a,b; Jaume and Boxshall, 1995a; Ohtsuka and Hiromi, 1987; Ohtsuka et al., 1993a,1996; Riera et al., 1991). In addition, some of these taxa accommodate both hyperbenthic and cavernicolous species (Ohtsuka et al., 1993b,1994; Yeatman, 1969). Such a faunistic similarity between in the hyperbenthic zone and marine caves strongly supports the above assumption.

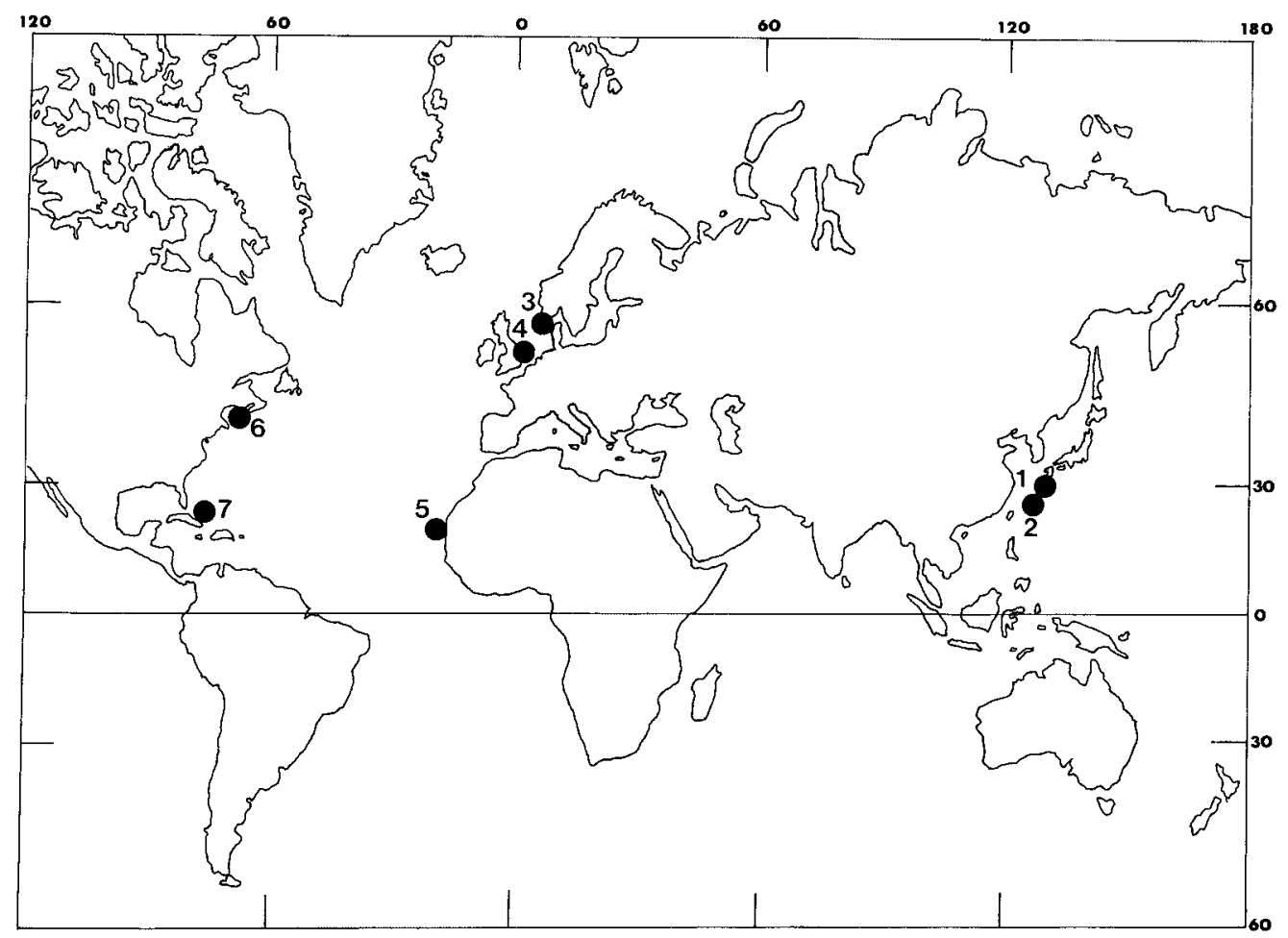

Fig. 7. Distribution of the genus Platycopia based on Huys and Boxshall (1991), Ohtsuka and Boxshall (1994) and present study. 1, $P$. compacta, n. sp.; 2, P. orientalis Ohtsuka and Boxshall; 3, P. perplexa Sars and P. pygmaea Sars; 4, P. perplexa; 5, $P$. robusta Andronov; $6, P$. sarsi Wilson and $P$. tumida Wilson; 7, $P$. inornata Fosshagen. 


\section{ACKNOWLEDGMENTS}

We would like to express our sincere thanks to $\operatorname{Dr}$ G.A. Boxshall for his revision of the early draft. Acknowledgments are also due to Dr F.D. Ferrari and an anonymous referee. We are grateful to the captain and crew of Toyoshio-maru, Hiroshima University for their cooperation at sea.

\section{REFERENCES}

Andronov VN (1985) Benthic Copepoda in the area of Cape Blanc (Islamic Republic of Mauritania) 1. The family Platycopiidae. Zool Zh 64: 1735-1739

Bowman TE (1976) Miostephos cubrobex, a new genus and species of copepod from an anchialine pool in Cuba (Calanoida: Stephidae). Proc Biol Soc Wash 89: 185-190

Bowman TE, González JG (1961) Four new species of Pseudocyclops (Copepoda, Calanoida) from Puerto Rico. Proc US Natn Mus 113: $37-59$

Boxshall GA (1989) Colonization of inland marine caves by misophrioid copepods. J Zool Lond 219: 517-526

Boxshall GA, Stock JM, Sanchez E (1990) A new species of Stephos Scott, 1892 (Copepoda: Calanoida) from an anchialine lava pool on Lanzarote, Canary Islands. Stygologia 5: 33-41

Ferrari FD (1988) Developmental patterns in numbers of ramal segments of copepod post-maxillipedal legs. Crustaceana 54: 256293

Ferrari FD (1995) Six copepodid stages of Ridgewayia klausruetzeri, a new species of copepod crustacean (Ridgewayiidae: Calanoida) from the barrier reef in Belize, with comments on appendage development. Proc Biol Soc Wash 108: 180-200

Ferrari FD, Markhaseva EL (1996) Parkius karenwishnerae, a new genus and species of calanoid copepod (Parkiidae, new family) from benthopelagic waters of the eastern tropical Pacific Ocean. Proc Biol Soc Wash 109: 264-285

Fosshagen A (1968a) Marine biological investigations in the Bahamas. 4. Pseudocyclopidae (Copepoda, Calanoida) from the Bahamas. Sarsia 32: 39-62

Fosshagen A (1968b) Marine biological investigations in the Bahamas. 8. Bottom-living Arietellidae (Copepoda, Calanoida) from the Bahamas with remarks on Paramisophria cluthae T. Scott. Sarsia 35: 57-64

Fosshagen A (1970a) Marine biological investigations in the Bahamas. 12. Stephidae (Copepoda, Calanoida) from the Bahamas with remarks on Stephos sinuatus Willey and S. arcticus Sars. Sarsia 41: 37-48

Fosshagen A (1970b) Marine biological investigations in the Bahamas. 15. Ridgewayia (Copepoda, Calanoida) and two new genera of calanoids from the Bahamas. Sarsia 44: $25-58$

Fosshagen A (1972) Marine biological investigations in the Bahamas 17. Platycopiidae (Copepoda, Calanoida) from the Bahamas. Sarsia 48: 51-60

Fosshagen A, lliffe TM (1985) Two new genera of Calanoida and a new order of Copepoda, Platycopioida, from marine caves on Bermuda. Sarsia 70: 345-358

Fosshagen A, lliffe TM (1988) A new genus of Platycopioida (Copepoda) from a marine cave on Bermuda. Hydrobiologia 167/ 168: 357-361

Fosshagen A, lliffe TM (1989) Boholina, a new genus (Copepoda: Calanoida) with two new species from an anchialine cave in the Philippines. Sarsia 74: 201-208

Fosshagen A, lliffe TM (1991) A new genus of calanoid copepod from an anchialine cave in Belize. Bull Plankton Soc Japan Spec Vol: 339-346
Fosshagen A, lliffe TM (1994) A new species of Erebonectes (Copepoda, Calanoida) from marine caves on Caicos Islands, West Indies. Hydrobiologia 292/293: 17-22

Hayami I, Kase T (1993) Submarine cave Bivalvia from the Ryukyu Islands; systematics and evolutionary significance. Bull Univ Mus, Univ Tokyo 35: 1-133

Ho JS (1994) Origin and evolution of the parasitic cyclopoid copepods. Int J Parasitol 24: 1293-1300

Huys R, Boxshall GA (1991) Copepod Evolution. The Ray Society, London

Jaume D, Boxshall GA (1995a) A new species of Exumella (Copepoda: Calanoida: Ridgewayiidae) from anchialine caves in the Mediterranean. Sarsia 80: 93-105

Jaume D, Boxshall GA (1995b) Stygocyclopia balearica, a new genus and species of calanoid copepod (Pseudocyclopiidae) from anchihaline caves in the Balearic Islands (Mediterranean). Sarsia 80: 213-222

Jaume D, Boxshall GA (1996a) Two new genera of cyclopinid copepods (Crustacea) from anchihaline caves on western Mediterranean and eastern Atlantic islands. Zool J Linnean Soc 117: 283304

Jaume D, Boxshall GA (1996b) The persistence of an ancient marine fauna in Mediterranean waters: new evidence from misophrioid copepods living in anchihaline caves. J Nat Hist 30: 1583-1595

Ohtsuka S, Hiromi J (1987) Calanoid copepods collected from the near-bottom in Tanabe Bay on the Pacific coast of the middle Honshu, Japan. Publ Seto Mar Biol Lab 32: 219-232

Ohtsuka S, Fosshagen A, lliffe TM (1993a) Two new species of Paramisophria (Copepoda, Calanoida, Arietellidae) from anchialine caves on the Canary and Galapagos Islands. Sarsia 78: $57-67$

Ohtsuka S, Roe HJS, Boxshall GA (1993b) A new family of calanoid copepods, the Hyperbionycidae, collected from the deep-sea hyperbenthic community in the northeastern Atlantic. Sarsia 78: 69-82

Ohtsuka S, Boxshall GA (1994) Platycopia orientalis, new species (Copepoda: Platycopioida), from the North Pacific, with descriptions of copepodid stages. J Crustacean Biol 14: 151-167

Ohtsuka S, Boxshall GA, Roe HSJ (1994) Phylogenetic relationships between arietellid genera (Copepoda: Calanoida), with the establishment of three new genera. Bull Nat Hist Mus Lond (Zool) 60: 105-172

Ohtsuka S, Fosshagen A, Soh HY (1996) Three new species of the demersal calanoid copepod Placocalanus (Ridgewayiidae) from Okinawa, southern Japan. Sarsia 81: 247-263

Riera T, Vives F, Cili J-M (1991) Stephos margalefi sp. nov. (Copepoda: Calanoida) from a submarine cave of Majorca Island (western Mediterranean). Oceanologia Aquatica 10: 317323

Rocha CEF, Iliffe TM (1991) Speleoithonidae, a new family of Copepoda (Cyclopoida) from anchialine caves on the Bahama Island. Sarsia 76: 167-175

Sars GO (1911) Platycopia perplexa, n. gen. and sp. A remarkable new type of deep-water Calanoida from the Norwegian coast. Archiv Math Naturv 31: 1-16

Stock JH (1993) Some remarkable distribution patterns in stygobiont Amphipoda. J Nat Hist 27: 807-819

Wilson, MS (1946) The species of Platycopia Sars (Copepoda, Calanoida). Smithson Misc Coll 106: 1-16

Yeatman HC (1969) A redescription of copepod, Ridgewayia marki, with description of an unusual specimen. J Tennessee Acad Sci 44: 7-10

(Received September 29, 1997 / Accepted February 2, 1998) 